\title{
LOS CAMPESINOS DE AYACUCHO Y LA GUERRA DEL PACÍFICO: REFLEXIONES DESDE (Y SOBRE) LA TEORÍA DE LOS ESTUDIOS SUBALTERNOS
}

\author{
AYACUCHO PEASANTS AND THE PACIFIC WAR: REFLECTIONS \\ FROM (Y ON) THE SUBALTERN STUDIES THEORY
}

\author{
Nelson Pereyra Chávez*
}

\begin{abstract}
La teoría de los estudios subalternos aparece como la más acorde para el estudio de las experiencias políticas de los campesinos, aunque muchos de sus enunciados no resultan novedosos en la historiografía relativo a los países andinos. A partir de tal referente teórico, el presente artículo intenta estudiar la participación de los campesinos de la región de Ayacucho (en la sierra sur central del Perú) en la guerra del Pacífico, tomando en cuenta las variables de la recurrencia judicial y la memoria decimonónicas. Propone que dicha participación condensó intereses, expectativas, discursos y representaciones de etapas previas, que tienen que ver con la relación entre campesinos y Estado republicano a raíz de los reclamos por la posesión de las tierras.
\end{abstract}

Palabras claves: Campesinos, guerra del Pacífico, estudios subalternos, gamonales, sociedad rural.

The theory of Subaltern Studies appears as the more appropriate for the study of the political experiences of peasants, although many of his statements are not novel in the historiography of the Andean Countries. This article studies the involvement of Ayacucho peasants (in the south-central highlands of Peru) in the Pacific War in the $19^{\text {th }}$ century, taking into account two variables: judicial recurrence and memory. From that theoretical reference, it proposes that such participation condensed interests, expectations, speechs and representations of preceding stages, which were relationed with the conexion between peasants and Republican State, following claims for possession of land.

Key words: Peasants, the Pacific War, Subaltern Studies, landowner, Rural Society.

\section{Introducción}

La teoría de los estudios subalternos, formulada en Inglaterra a fines de la década de 1970 por intelectuales indios (como R. Guha, P. Chatterjee, D. Chakrabarty o S. Amin) que estaban interesados en repensar la experiencia poscolonial de su país, se ha convertido en el referente teórico para el estudio de los sectores populares, ya que pretende restituir a los subalternos su condición de agentes plurales y descentrados y ponerlos en escena como los principales protagonistas de las realidades poscoloniales.

Tomando en cuenta sus proposiciones teóricas y método, en el presente artículo se pretende estudiar la participación de los campesinos de Ayacucho en la guerra del Pacífico (1879-1883) y en las décadas previas al conflicto, para constatar las posibilidades y limitaciones de dicha teoría y ofrecer nuevas perspectivas al análisis de la política campesina.

Es importante precisar que las reflexiones ofrecidas no parten de un punto cero. Al contrario, en la historiografía peruana existen trabajos acerca de la participación campesina en la guerra del Pacífico. En efecto, los historiadores N. Manrique (1981) y F. Mallon (2003) señalaron que la ocupación de la sierra central peruana por el ejército chileno generó un nacionalismo sui generis entre los campesinos, quienes se representaron como peruanos y combatieron a los chilenos. Pero dicho nacionalismo apareció en un territorio particular, donde aquellos, en permanente tensión con los hacendados, especializaron su producción y la dirigieron al mercado.

Ambos aportaron al conocimiento histórico al revelar que la participación campesina en el conflicto condensó intereses, expectativas y representaciones, y no fue una mera respuesta espasmódica a la presencia de tropas extranjeras o a las relaciones de dominación. Siguiendo esta línea y en el marco de la teoría de los estudios subalternos, en el presente artículo se propone que la movilización de los campesinos de Ayacucho contra las fuerzas chilenas fue el corolario de una agencia campesina que se desarrolló a lo largo del siglo XIX y que sintetiza la reinterpretación de un orden social

* Universidad Nacional de San Cristóbal de Huamanga, Ayacucho, Perú. Correo electrónico: nelsonernesto@ hotmail.com 
marginal, con sus prácticas y discursos alternativos y contrahegemónicos.

El área de estudio es la región de Ayacucho: un espacio de aproximadamente 47.842,23 $\mathrm{km}^{2}$, ubicado en la sierra sur central del Perú, estructurado a partir de capas sedimentadas de reconfiguración administrativo-territorial que vienen desde tiempos prehispánicos. Conformado en el siglo XIX por siete provincias (Andahuaylas, Cangallo, Huamanga, Huanta, La Mar, Lucanas y Parinacochas), poseía una población mayoritariamente campesina. En efecto, en 1827 el departamento de Ayacucho tenía 121.776 habitantes, con 69 por ciento de habitantes indígenas. En 1850 tenía 130.070 habitantes y en 1876 contaba con 198.315 habitantes, de ellos el 72 por ciento eran campesinos (Bonilla 1987, Gootenberg 1995).

\section{Una (breve) mirada a la teoría de los estudios subalternos}

Una de las propuestas centrales de la teoría de los estudios subalternos es la de restituir a los subalternos su condición de agentes plurales y descentrados. En su célebre ensayo, la crítica literaria G. Ch. Spivak (2003) define a los subalternos como personas que se encuentran en una situación de inferioridad por participar de la subalternidad, siendo esta última una forma de opresión simbólica y epistémica que ocurre especialmente en sistemas poscoloniales. En medio de la opresión, ellos no pueden expresarse ni valerse por sí mismos; tienen que hablar por medio de los que dicen representarlos, convirtiéndose en "significados sin significantes" (Silva Santisteban 2006: 136).

La teoría de los estudios subalternos no pretende hablar en nombre de los subalternos; al contrario, busca su misma representación como principales protagonistas de las realidades poscoloniales, ya que pueden plantear y desarrollar su propia agencia histórica de forma muy particular, sin involucrarse en la contingencia de las élites (Guha 1997). Dicha agencia manifiesta una pluralidad de voluntades que se entrecruzan y entremezclan con referentes culturales y simbólicos, tal vez "tradicionales", religiosos o "sobrenaturales", pero de ningún modo "arcaicos". Además, al ser puesta como particular, cultural y heterogénea, se acerca a los glocalismos que, en las actuales circunstancias, "traducen" (recrean) la contingencia uniformadora de la globalización.
Esta definición lleva a la teoría a cuestionar también la noción moderna de nación y plantear otro método para aprehender la voz de los subalternos. Respecto de lo primero, el crítico H.K. Bhabha y el historiador P. Chatterjee señalan que las sociedades no occidentales aportaron algo de imaginación en la construcción de las naciones. Este último agrega que los subalternos construyeron sus propias comunidades nacionales en forma paralela a las élites, a partir de elementos "espirituales" que generaron consensos y resignificaron los "formatos" modulares occidentales. Dichas comunidades, además, se transformaron en espacios "para la política de los subalternos [...] a partir del cual existe la necesidad de negociar acuerdos" (Chatterjee 2007: 101).

En cuanto al método, la teoría cuestiona la noción de contingencia ineludible del tiempo histórico y el empleo del modelo secuencial. Postula la existencia de múltiples y disímiles tiempos enmarañados a modo de un nudo. Propone, además, separar el hecho histórico de la concatenación de secuencias que forman la contingencia, para aprehenderlo en aislamiento o en fragmentación total y así encontrar precisamente la voz plural del agente subalterno o representar "los pequeños dramas y los sutiles detalles que caracterizan a la vida social, especialmente en sus recovecos más soterrados" (Guha 1999: 52).

Si bien el método intenta rescatar los signos de los mismos subalternos, finalmente consolida el empleo de la hermenéutica en la Historia. En efecto, la decodificación de los signos de los subalternos, inscritos en los documentos, no forma parte de una única estrategia deconstruccionista de la textualidad. $\mathrm{Al}$ contrario, contiene procedimientos interpretativos que intentan obtener descripciones precisas centradas en el sentido que los mismos actores adjudican a sus actos. Forman parte de la antropología interpretativa de C. Geertz, que busca desentrañar estructuras de significación variada, extrañas, irregulares, no explícitas y que deben ser captadas y explicitadas luego (2003: 24). Y en nuestro caso, doblemente irregulares, porque provienen de los estratos más bajos de la sociedad y están plasmados en documentos en la mayoría de los casos elaborados por otros.

En la historiografía peruana son F. Mallon (2003) y M. Thurner (2006) quienes han recurrido a la teoría de los estudios subalternos para estudiar la cultura política de los campesinos de Huaylas y Junín, afectados por la guerra del Pacífico. Ambos sugieren que estos pobladores dialogaron con el 
Estado mediante sus propias "comunidades republicanas" dinámicas, heterogéneas, contrahegemónicas, conflictivas y también negociadoras. Esta negociación es para Thurner un "pacto republicano" que articulaba a la comunidad con el Estado. Y dicho pacto no es otra cosa que el "pacto tributario": una forma de reciprocidad en donde el Estado cobraba la contribución indígena y los campesinos lograban la protección de sus tierras. El modelo del "pacto tributario", originalmente suscrito por T. Platt en su investigación acerca de los ayllus de Potosí, ha sido reproducido por los historiadores peruanos para estudiar la articulación de las comunidades campesinas (Contreras 1989) o la burocracia regional del Estado republicano (Peralta 1991).

Ante tal panorama, vale explorar otras formas de articulación campesina, que van más allá del pacto tributario y grafican su agencia en el discurrir del siglo XIX o en la etapa de la guerra del Pacífico. La experiencia de los campesinos decimonónicos de Ayacucho acude en ayuda nuestra.

\section{Los campesinos de Ayacucho en el siglo XIX}

\section{La guerra toca las puertas de la región}

La guerra del Pacífico, que empezó en el extremo meridional del Perú con las campañas marítima y terrestre, no fue desconocida por los campesinos ayacuchanos. Ellos, al inicio del conflicto, colaboraron con víveres, dinero y combatientes; p.ej., en 1880 los "vecinos notables" y campesinos del distrito de Huamanguilla (provincia de Huanta) enviaron una columna de campesinos para la defensa de Lima (Del Pino 1994: 6).

Cuando en enero de 1881 el ejército chileno ocupó Lima, la guerra tocó las puertas de la región. El dictador Nicolás de Piérola se retiró a la sierra e instaló la Asamblea Nacional en Ayacucho. Mientras tanto, el general Andrés A. Cáceres empezó a organizar la resistencia de la Breña con el concurso de terratenientes, campesinos y guerrilleros de Huancayo, Huancavelica y Huanta, logrando mantener el control político y militar de la sierra central peruana entre 1882 y 1883 . Sin embargo, las fuerzas de la resistencia fueron finalmente derrotadas en la batalla de Huamachuco, el 10 de julio de 1883, en medio de una nueva circunstancia política: cuando el hacendado cajamarquino Miguel Iglesias propuso la paz con Chile con cesión territorial.
Luego de la batalla, Cáceres se retiró a Ayacucho y Andahuaylas con la intención de formar un nuevo ejército, siendo perseguido por las fuerzas del coronel Martiniano Urriola, que salieron de Huancayo y en su recorrido pasaron por los pueblos de Acobamba, Marcas y Huanta hasta llegar a la ciudad de Ayacucho, siendo hostilizados por guerrilleros campesinos comandados por el terrateniente y líder cacerista Miguel Lazón. El corresponsal del periódico El Mercurio de Valparaíso, quien acompañó a Urriola en su expedición a Ayacucho, refiere que la tropa chilena avanzaba "haciendo retroceder a los montoneros que en grueso número y armados de fusiles, hondas y lanzas pretendían estorbarles el paso" (citado en Del Pino 1955: 70). Al ocupar el pueblo de Huanta el 27 de setiembre de 1883, fue recibida por el alcalde Manuel Quirosongo y un grupo de terratenientes y "vecinos notables" que prefirió colocarse bajo el manto protector de los extranjeros.

Los chilenos ocuparon la ciudad de Ayacucho el $1^{\circ}$ de octubre de 1883 , "sin disparar ni un tiro de fusil porque no había ni un solo hombre dispuesto a oponer resistencia al paso del conquistador" (Cavero 1953: 255). Debido a la carencia de víveres y forraje, emprendieron la retirada al norte, pasando nuevamente por Huanta y siendo otra vez atacados por las guerrillas.

La presencia de las tropas chilenas en el territorio de Ayacucho ocasionó la polarización de la sociedad regional y la reaparición de tensiones sociales. Los campesinos de Huanta combatieron a los chilenos en alianza con un grupo de hacendados partidarios de Cáceres, mientras que la otra facción de terratenientes de esta provincia, junto con hacendados y campesinos de Huamanga y Cangallo, no opusieron resistencia a los invasores. En junio de 1882, en el pueblo de Concepción (provincia de Cangallo), la hacendada de Paccomarca y su esposo el gobernador Manuel Pacheco fueron atacados por una turba de más de 30 personas porque obligaban a la población a organizarse para enfrentar a los chilenos (Archivo Regional de Ayacucho, en adelante ARAy, Corte Superior de Justicia, 1882, leg. 245, s/FF). ¿Por qué tales actitudes divergentes? ¿Acaso tienen que ver con la experiencia histórica previa?

\section{Conflictos y estrategias de comunalización}

La movilización de los campesinos de Ayacucho a favor y en contra de la resistencia fue el corolario 
de acciones y estrategias decimonónicas, usadas para acudir a la justicia del Estado y defender la posesión de sus tierras, que se complementaron con discursos y representaciones cuestionadoras del poder hegemónico de los terratenientes.

La estructura rural de la región de Ayacucho devela la existencia de medianas y pequeñas propiedades detentadas por criollos mestizos y campesinos. En efecto, en la provincia de Huamanga existían 173 haciendas y 20 hatos ganaderos, según el padrón de contribuyentes de 1826. En las norteñas provincias de Huanta y La Mar los padrones de 1869-1879 registran la cantidad de 249 propiedades y 47 haciendas orientadas al cultivo de caña y producción de aguardiente. Hacia el sur, en el extenso territorio de Cangallo, había 31 haciendas productoras de gramíneas y caña y 131 hatos de ganado. Y más al sur, en las lejanas jurisdicciones de Lucanas y Parinacochas, existían más de 500 predios rurales, entre haciendas y chacras, orientadas al cultivo de alfalfa y a la producción agropecuaria.

Aunque las relaciones laborales reposaban en el alquiler de la hacienda a colonos que se hacían cargo de la producción y además trabajaban como sirvientes de los hacendados, a menudo estos contrataban a peones campesinos a cambio de un jornal. Es el caso de José Palomino, gobernador de Tambillo y arrendatario de la hacienda de Yanamilla, quien en 1840 "se sirvió de Mariano N., residente en Tambillo, por cuatro días por una peseta diaria que le daba $[\ldots]$ y de cuantos concurren voluntariamente porque les paga religiosamente sus hornales [sic]" (ARAy, Juzgado de Primera Instancia, 1840, leg. 46, c. 920, f. 6r).

En medio de este mar de propiedades, subsistían las tierras de los campesinos, también arrendadas, pero a locadores criollos y mestizos; p. ej. El fundo de Sapsi, ubicado en el distrito de Huamanguilla (Huanta), que fue alquilado por los alcaldes, regidores y alguaciles de la comunidad a Domingo Oré "por tiempo de nueve años, cinco forzosos y cuatro voluntarios" (ARAy, Juzgado de Primera Instancia, 1843, leg. 18, c. 341, f. 1v).

Estas haciendas se formaron entre los siglos XVI y XVII, con las composiciones de tierras que fomentaron la aparición de la propiedad privada. Más adelante fueron afectadas por las disposiciones agrarias de los reyes borbones, que pretendían desamortizar y parcelar las tierras de corporaciones, pueblos, mayorazgos y comunes para consolidar la propiedad privada, pero manteniendo la cooperación entre productores (Jacobsen 1991: 33). Estas disposiciones ocasionaron en la región la fragmentación de la propiedad. En efecto, los documentos de fines del siglo XVIII e inicios del XIX revelan la aparición de numerosos predios rurales, concomitantes con situaciones y conflictos de herencias y sucesiones, y legitimados por la autoridad colonial mediante nuevas composiciones de tierras. Es el caso de los predios de Francisco Meneses, "ciudadano de la villa de Huanta", quien en su testamento alegó tener unas tierras llamadas Comunpampa, "compuestas con el rey por ante el gobernador subdelegado don Bernardino Estevanes de Cevallos" en mayo de 1815, en la cantidad de 150 pesos (ARAy, Corte Superior de Justicia, 1850, leg. 16, f. 2r).

Más adelante, con la ley agraria liberal de 1828 (que desamortizaba las tierras comunales a beneficio de los indios y mestizos que las usufructuaban), se acentuaron las disputas por la tierra, porque la norma propició la aparición de un débil mercado de tierras (pese a que prohibía el intercambio libre de predios entre los nuevos propietarios que eran analfabetos) o, peor aún, alentó la usurpación de tierras de los campesinos (Jacobsen 2013: 210). En efecto, la estadística revela el incremento de la curva de conflictos judiciales que involucran a comunidades campesinas entre 1833 y 1855 , para luego caer abruptamente y recuperarse tras la guerra del Pacífico. En dicha curva se hallan juicios intercomunales por tierras, quejas contra autoridades, demandas por tributos, litigios entre comunidades y haciendas, pleitos entre comunidades y curas, casos de abigeato y otros similares (Urrutia 2014: 215).

Aunque tal nivel de conflictividad presenta matices de acuerdo con la ubicación geográfica de las comunidades, no niega el impacto de la ley agraria de 1828 en la estructura de la propiedad rural y el interés de los campesinos por preservar su acceso a los recursos con la intervención del Estado republicano.

Un caso interesante es el largo juicio entre los campesinos de Quinua (en la provincia de Huamanga) y la hacendada Isabel Aedo por las tierras de Ahuaccollay. En 1850 el apoderado de los campesinos Cipriano de Valdivia demandó a la hacendada por haberse apropiado del predio sin otro instrumento que el testamento de su difunto esposo Pedro Castro y Coronado, que -según el demandante- ratificaba la propiedad campesina de la tierra y la condición de arrendatarios de Castro y Aedo. En su defensa, el abogado Ambrosio de 
Rivera pidió tomar en cuenta a Francisco Coronado, sobrino y legatario del finado Castro, quien -según el letrado- era el verdadero propietario del predio.

Tras escuchar a las partes, el Juez de Primera Instancia de las provincias de Huamanga, Huanta y Cangallo sentenció a favor de los campesinos de Quinua. Combinando las Leyes de Indias y la norma agraria de 1828 , dispuso que la demandada "restituya las tierras a la indicada comunidad" y pague la deuda por el canon conductivo de 10 años. Agregó lo siguiente:

Tercero, que la constitución de censo reservativo requiere propiedad y pleno dominio del que lo constituye y las comunidades de los pueblos, ni por las Leyes de Indias, ni por las ordenanzas del Perú, han tenido esa propiedad y pleno dominio en las tierras de la naturaleza de Ahuaccollay, resultando inoficiosas y negatorias las pruebas producidas por la demanda, por recibos que no han tenido ni han podido tener existencia [...] ante la Ley patria de veintisiete de marzo de mil ochocientos veintiocho, que declara propiedad de indios y mestizos de las tierras que entonces alegaban por repartos o sin contradicciones, exceptúa de este derecho a los que ocupaban tierras por razones de oficio. Cuarto, que por lo expuesto, siendo las comunidades meras usufructuarias de las tierras que ocupaban, no han podido transferir más que esta regalía precaria a don Pedro Castro Coronado o sus ascendientes (ARAy, Corte Superior de Justicia, 1850, leg. 17., ff. 61v-62r).

El juez reconoció la situación real de unas tierras comunales originadas en un repartimiento colonial. En efecto, la hacienda Ahuaccollay estaba integrada por varias propiedades, cuyos ocupantes tenían derecho a una "acción" (Diez 1998: 72). Sin embargo, evitó definir explícitamente su carácter de propiedad para no parcelar la tierra o no propiciar la formación de pequeñas propiedades privadas. Al contrario, insistió en mantener la propiedad colectiva "por razón de tributos o contribución"; es decir, para que los campesinos renovasen su pacto tributario con el Estado (ARAy, Corte Superior de Justicia, 1850, leg. 17, f. 161v).

Por supuesto que esta sentencia fue cuestionada por el abogado de Aedo, porque consideraba a los campesinos como propietarios y usufructuarios a la vez. Con la apelación, el juicio se prolongó y las partes se enfrascaron en una contienda con "instrumentos históricos" para intentar probar, cada cual, su respectivo punto de vista. Doce años después, el caso fue solucionado cuando el nuevo apoderado de los campesinos, Bartolomé Galván, y el hijo de doña Isabel, Ambrosio Aedo, conciliaron y decidieron que "continuará poseyendo la parte demandada los fundos litigados de Ahuaccollay, con solo la condición de saldar los censos devengados [...]" (ARAy, Corte Superior de Justicia, 1862, leg. 34, f. 21r).

Como se mencionó antes, el Juez de Primera Instancia con su sentencia legitimó un hecho fáctico: la existencia de varios "accionistas" campesinos, usufructuarios de parcelas dentro de los límites de la propiedad comunal. Un juicio adicional por las parcelas de Usvicancha y Antayccacca, que empezó en 1856, ayuda a ilustrar esta estructura.

En aquel año, el apoderado de los campesinos, Cipriano de Valdivia, interpuso otra demanda contra Isabel Aedo por usurpar los mencionados predios. El abogado de la demandada retrucó, indicando que la demanda no fue interpuesta por aquel, sino por un campesino llamado Lorenzo Ayme y que los terrenos no formaban parte de las posesiones del común de Quinua, sino de una loma llamada también Antayccacca, que era propiedad particular de Aedo. Valdivia afirmó que Uviscancha y Antayccacca eran una "acción" en propiedad comunal, que habían sido adquiridos hace dos siglos por Agustín Vilca, el lejano ascendiente de los hermanos María, Francisco y José Ayme, sus actuales reclamantes. El juez revalidó este alegato al confirmar la acción de Uviscancha y Antayccacca como perteneciente a la hacienda de Ahuaccollay, en litigio entre los campesinos de Quinua y la hacendada Aedo.

El caso grafica el impacto de la legislación republicana en la estructura agraria de Ayacucho. Además, devela la intervención del Estado en las disputas entre hacendados y campesinos, no siempre inclinando la balanza de la justicia a favor de los primeros. Ello resulta revelador, ya que en el siglo XIX los jueces eran, en la mayoría de los casos, los mismos hacendados denunciados. Es que el caso sugiere abandonar la canónica definición del Estado, como asociación controlada por los grupos dominantes o que monopoliza el uso de la violencia, para buscar otro concepto que incluya distintas dimensiones, como los sectores populares o la misma cotidianeidad. 


\section{La formación cotidiana del Estado}

Dicho concepto es el de formación cotidiana del Estado, que alude a las prácticas y discursos que emplea el Estado para regular en la cotidianeidad la vida de sus ciudadanos y definir la identidad de sus subordinados (Joseph y Nugent 2002: 31-52). Dichas prácticas y discursos son transmitidos por la administración cotidiana, los rituales y los medios de comunicación a los ciudadanos que se hallan en el extremo opuesto de la cadena de relaciones y se han convertido en el objeto de poder del Estado (Nugent y Alonso 2002: 176).

Normas como las disposiciones agrarias de 1828 conformaron aquellas prácticas y discursos estatales. En la práctica consolidaron entre los campesinos la noción de propiedad y sirvieron para que reclamasen la posesión de la tierra y legitimasen su usufructo individual. En 1872, p. ej., los campesinos del pago de Chihua (en Huanta) demandaron al hacendado Fidel Zagastizábal, con la ley agraria en la mano, por haberse apropiado de sus tierras (ARAy, Corte Superior de Justicia, 1872, leg. 52, ff. 33r-34r). Es que dichas normas fueron conocidas por los habitantes de la zona rural. Llegaron a localidades tan lejanas como Quinua o Chihua con el equipaje de comerciantes y arrieros, que intecambiaban bienes de pueblo en pueblo, o con el portafolio de "agentes pleitos" que recorrían el interior de la región buscando patrocinados y casos por litigar.

Estas normas, socializadas entre campesinos en la rutina cotidiana, inspiraron pleitos judiciales con los hacendados, que en la mayoría de las veces fueron emprendidos por los mismos campesinos con el nombramiento de un apoderado. Ocurrió con los pobladores de Quinua, quienes en 1858 discutieron en cabildo abierto la designación de Marcos Carrera como su apoderado en el largo juicio contra la hacendada Aedo (ARAy, Corte Superior de Justicia, 1858, leg. 28, f. 38v).

Luego de designar al apoderado y presentar la demanda, los campesinos empezaban a recorrer los laberintos de la justicia formal del Estado republicano, participando de un prolongado ritual conjuntamente con abogados, jueces, fiscales y procuradores, que asumían particulares roles performativos. Basta con recordar que el juicio entre los campesinos de Quinua e Isabel Aedo duró 12 años y tuvo varias fases. Empezó en un Juzgado de Primera Instancia con la denuncia y alegatos de ambas partes; siguió con un deslinde in situ; subió a una instancia superior; regresó al Juzgado de Primera Instancia y culminó con una conciliación parcialmente aceptada por una de las partes.

Con normas y juicios el Estado reprodujo en la cotidianeidad discursos y prácticas ordenantes de las acciones de hacendados y campesinos. Al mismo tiempo, permitió dentro de su marco cultural y discursivo reclamos y enunciados de ambos actores sociales y especialmente de campesinos tendientes a legitimar la propiedad. No obstante, la mayoría de las veces los denunciados y encargados de hacer justicia fueron los mismos hacendados, conformantes de un sistema gamonal que transformaba la forma cotidiana del Estado en una actuación ambigua o marginal.

\section{El gamonalismo en Ayacucho}

Con gamonalismo se designa a una forma de poder local personalizada, que reposaba en el acceso de ciertos individuos a los recursos, en el control que ejercían sobre las instituciones estatales y en el uso de la violencia a su favor (Poole 2009: 608). Sin embargo, dicha imagen va asociada a la representación que las élites regionales elaboraron respecto de los gamonales: la de mestizos que se convirtieron en hacendado por medio del fraude y del engaño y que carecían de los valores morales de la decencia y el respeto (De la Cadena 2004: 99), representación que además ha sido reproducida por la literatura historiográfica (Burga y Flores Galindo 1990, Manrique 1988).

Dicha imagen debe ser usada con cautela, desde el punto de vista de la evidencia empírica y teniendo en cuenta que el Estado se reprodujo en el interior del país mediante formas discursivas, normas y símbolos que llegaron hasta la población campesina en medio de reclamos judiciales, como acabamos de ver. En tal sentido, se debe precisar cómo esta reproducción cotidiana del Estado empata o se contradice con el gamonalismo imperante.

El gamonalismo apareció en Ayacucho con aquellas dinámicas de apropiación de la tierra mencionadas anteriormente y gravitó en el uso de la violencia hacia los campesinos. A menudo, los gamonales eran también autoridades estatales. Es el caso del mencionado José Palomino, gobernador del distrito de Tambillo y arrendatario de la hacienda de Yanamilla, quien en 1840 fue denunciado por el alcalde auxiliar José Cancho por haberlo despedido y por azotar a sus alguaciles Isidro Anaya y Melchor Rojas, "por el mismo delito de no haber estado a 
todas horas en su casa a prestar los servicios domésticos" (ARAy, Juzgado de Primera Instancia, 1840, leg. 46, c. 920, f. 1v). El acusado sostuvo que depuso a Cancho por no haberle entregado la contribución que recolectó como alcalde auxiliar y ayudante del gobernador.

Los denunciantes por propia voluntad llevaron el caso ante un Poder Judicial que administra justicia a nombre del Estado peruano, pese a que los jueces eran los mismos gamonales. Así, los acusados se convirtieron en "juez y parte" al desarrollar una "justicia marginal"; es decir, prácticas que combinan marcos teóricos legales con procedimientos extralegales, la justicia pública con la justicia privada. En el Perú, lamentablemente dichas prácticas coincidían (y coinciden todavía) con las poblaciones que se hallan físicamente alejadas de la capital de la República o de los centros de poder económico (Poole 2009: 608).

Por ser las únicas existentes y por estar legitimadas por el Estado, dichas prácticas de justicia marginal fueron aceptadas por la población, pero a la vez negadas por poseer esa áurea de simultaneidad. Los demandados, al ser también administradores de justicia, se convertían en garantía y amenaza.

El caso de Palomino, citado líneas arriba, ayuda a clarificar esta percepción. Él, como autoridad del Estado, estaba encargado de recolectar el tributo, velar por el orden interno y reclutar mano de obra para las obras públicas. Además, debía resolver los pleitos por conflictos menores, como las pequeñas disputas intrafamiliares. Pero al mismo tiempo era hacendado y se apoderaba de la mano de obra y recursos del distrito para su beneficio.

Insistimos: los campesinos acudían voluntariamente a la justicia marginal del Estado para denunciar a los gamonales-autoridades, pese a que estos eran amenaza y garantía a la vez. En el caso que nos ocupa, Palomino fue sentenciado por el Juez de Primera Instancia, aunque apeló, la decisión y terminó dilatando el proceso.

Finalmente, el surgimiento del gamonalismo en la región de Ayacucho ocurrió precisamente cuando la estructura social fue modificada por la aparición de actores sociales beneficiados con el incremento del comercio de ganado y trigo, durante el boom del guano, y portadores de un discurso liberal que todavía no ha sido suficientemente estudiado (Del Pino 1993). Para la provincia de Huanta Patrick Husson (1992) constata la aparición de un nuevo grupo social de terratenientes mestizos que intentó acrecentar su capital en tierras y estatus, compitiendo con la antigua aristocracia local. Para ello contó con el apoyo de los campesinos. La competencia devino en una vendetta política que enfrentó a las dos familias rivales que alinearon ambas fuerzas sociales en pugna: los Arias, que reunieron a la antigua aristocracia venida a menos, y los Lazón, que eran los mestizos que pugnaban por materializar sus aspiraciones políticas y sociales. Fueron estos últimos los que enfrentaron a los chilenos durante la guerra del Pacífico, mientras los primeros pactaron con los extranjeros.

\section{Las batallas por la memoria}

La defensa campesina de la tierra activó un proceso en el que los recuerdos y narrativas del pasado fueron organizados por los mismos individuos en una "memoria emblemática" modelada y reforzada con diversos documentos extraídos del archivo comunal o de repositorios de notarios de Ayacucho, Huanta o San Miguel. Dicha memoria fue integrada al expediente judicial como prueba histórica y aparentemente irrefutable en la defensa de la tierra.

Ello ocurrió en el largo proceso judicial que enfrentó a los campesinos de Quinua con la hacendada Isabel Aedo por las tierras de Ahuaccollay. En uno de sus alegatos, la demandada pidió ver un expediente organizado en el siglo XVIII por los caciques Melchor Guayllasco y Pablo Guasaca sobre las tierras de Quinua, que contenía varios escritos: pedidos de Juan Camacachín y Rodrigo Paucartanqui (esposo de Magdalena Choquetinta) asociado a las tierras de Suso; denuncias contra el curaca Pablo Guasaca; descargos, balances, entre otros instrumentos.

Según la memoria de los campesinos, la propiedad colectiva de las tierras de Ahuaccollay se remontaba a 1618, cuando Juan Camacachín, como yerno de Magdalena Choquetinta -hija del curaca Cristóbal Checa-demandó la posesión de las tierras de Suso. Sin embargo, Camacachín fue desmentido en aquella ocasión por el esposo de Choquetinta, Rodrigo Paucartanqui, quien no solo cuestionó su ascendencia forastera, sino mencionó lo siguiente:

[...] que las dichas tierras y chacra llamada Susso sobre que se litiga con el dicho Pedro Huamán Camacachi zapatero fueron y son de la dicha Magdalena Choquetinta, heredadas de su padre y abuelos desde el 
tiempo del ynga porque se las dio el mismo ynga por ser como era criado suyo y guardaba a los pájaros y otras aves que el dicho ynga Ataguallpa tenía para su recreación y por esta probanza se las mandó dar y se las dio. Un casicho [sic], un cacique señor que el dicho ynga envió visitando esta tierra y por mandato del dicho ynga se les dio y adjudicó las dichas tierras de Suso y otras que tuvo a Halaca, abuelo de Magdalena Choquetinta, que al presente vive y heredó las dichas tierras de Suso. Y el dicho Halaca, que será gentil, se las dejó a su hijo Cristóbal Chuca padre de la dicha Magdalena y esto cosa de tiempo, porque como cacique principal se informó y está informado de todos los viejos antiguos que los saben y que después como hija legítima de Cristóbal Chuca las heredó el dicho su padre y esto responde (Ídem., f. 12r).

Aunque esta versión fue confirmada en su debido momento por el encomendero Pedro Díez de Rojas y por el principal del ayllu Hanansayocc Domingo Cóndor Víñac, no fue suficiente para que los campesinos del siglo XIX inclinaran la balanza de la justicia a su favor. Tuvieron que mencionar una impugnación de 1753 contra el cacique Pablo Guasaca por haber sido nombrado por el virrey Marqués de Villagarcía. Y acto seguido, trazaron una relación genealógica entre ellos, este jefe nativo, su padre Francisco Guasaca, su madre Rufina Guayllasco y su abuelo materno Blas Guayllasco, el cacique principal del ayllu.

Como se habrá notado, ninguna de estos nobles indígenas de la colonia guarda relación con el reclamo de los campesinos decimonónicos por la propiedad de Ahuaccollay. Al contrario, los escritos del expediente mencionan las tierras de Suso y en una sola circunstancia (1753) señalan indirectamente el predio en disputa con Aedo para certificar que en el siglo XVIII ya existía el censo a beneficio del cabildo de indígenas. Entonces, ¿por qué Isabel Aedo exigió a mediados del siglo XIX la exposición de estos instrumentos?

Los campesinos del siglo XIX, al valorar la antigüedad y originalidad de sus instrumentos formulaban una definición cultural de la disputa, en contraposición a la intencionalidad cuasilegal que Aedo y Coronado le conferían al proceso ( $\mathrm{La}$ Serna, 2013: 257). Es decir, consideraban que las tierras de Suso y Ahuaccollay formaban una misma propiedad comunal simbólicamente asociada con aquellos caciques que eran considerados como los "ancestros" del grupo.

En efecto, en otro expediente elaborado por los campesinos de Quinua ya en el siglo XX a fin de lograr el reconocimiento de su comunidad por parte del Estado, se lee que los hermanos Suyro, herederos del cacique Pedro Suyro, solicitaron al juez visitador Gabriel Solano de Figueroa la composición de las tierras de Suso en 1595 y luego el cacique Francisco Guasaca pidió amparo y posesión de dicho predio en 1724. A continuación, en otro escrito de 1725, el cacique Sebastián Pablo Guasaca escribió (o mando escribir) lo siguiente al virrey Marqués de Villagarcía:

Dice que a los indios de su comunidad se le repartieron desde el año de mil setecientos treinta y cinco las tierras y pastos y hatos nombrados Ñahuinpuquio, Mayguayuna, Pamparay, Yanacocha, Mojoncancha, Urgospampa [sic], Llanavilca, Putacca, chacras con sus hatos y mojones, y otras en Quecra y Suso y Toctocancha, hatos de vacas con sus pastos y mojones para cabras y ovejas [...] que después por el año de setecientos treinta y seis se confirió y mandó por cesión el señor doctor don Andrés de Villela, juez privativo y visitador de las tierras de aquellas provincias, en cuya virtud han estado en goce y posesión repartiéndolas continuamente a los indios para que las siembren y se mantengan y puedan cumplir las obligaciones y servicios personales de puentes, chasquis y otras funciones, como también la paga de rentas y tributos [...] (Archivo de la Dirección Regional Agraria de Ayacucho, Huamanga 42, f. 67v. El resaltado es mío).

En la cita, Guasaca es aludido como descendiente de los primigenios jefes nativos del lugar: don Pedro Suyro y sus hijos, quienes (en el recuerdo campesino) lograron la posesión de la propiedad comunal. Aquel Pablo Guasaca y este Sebastián Pablo Guasaca son la misma persona: el cacique que existió en tiempos del virrey José Antonio de Mendoza, Marqués de Villagarcía (1735-1745). La mención de este gobernante actúa como punto de referencia para localizar el recuerdo en relación 
con la tradición. De igual forma, la nominación de las tierras actúa como referencia para estructurar la posesión comunal y relacionar un hito con otro. El sitio de Urgospampa no viene a ser otro que Higospampa o Uviscancha; es decir, la loma que forma parte del predio de Ahuaccollay y por la que litigan Aedo y los Ayme. Por ello, la hacendad se interesa en observar los instrumentos de los campesinos demandantes.

Las memorias contienen una contraparte de silencios, que revela manejo de poder en la construcción de las narrativas del recuerdo, ya que se intenta encubrir aquello que no se quiere recordar o genera molestia y rechazo (Trouillot 1995). En el caso, Aedo quiso silenciar el motivo que provocó tan extenso juicio: la invasión a los pastos de Antayccacca que hacia 1776 protagonizó su suegro, el cura Diego Castro, complementada con la apropiación que su marido Pedro Castro Coronado hizo de las tierras de Ahuaccollay y Uviscancha, convirtiendo a los Ayme en yanaconas de su nueva propiedad privada.

\section{A modo de conclusión}

La actuación política campesina, relacionada con su resistencia a los gamonales en el marco de la formación cotidiana del Estado, continuó cuando el territorio de la región se convirtió en un "apéndice" de la resistencia de la Breña. En efecto, aquellas estrategias políticas de emprendimiento no fueron obstáculo para que, p. ej., en Huanta o Quinua, donde existían pequeñas haciendas poseídas casi en igualdad de condiciones por gamonales y campesinos, estos últimos establecieran alianzas con una facción del grupo de poder local a fin de movilizarse en contra de los chilenos.

Dicho emprendimiento campesino contó además con la elaboración de una memoria, que logró congregar a los pobladores rurales en torno a la defensa de la tierra; es decir, estableció relaciones de solidaridad entre usufructuarios de un predio en común, actuó como catalizadora de las narrativas e intereses particulares y sirvió para definir las nociones de pertenencia a un colectivo y diferencia para con otro.
En tal sentido, los campesinos decimonónicos de Ayacucho no estructuraron una "comunidad republicana" alternativa u opuesta al Estado poscolonial, basada en la alteridad, la particularidad y la "tradicionalidad" como características centrales, como sugiere la teoría de los estudios subalternos. $\mathrm{Al}$ contrario, dialogaron y reprodujeron las pautas culturales del Estado, acudieron a las instancias judiciales estatales y hasta utilizaron su discurso de justicia oficial para pleitear con los gamonales y lograr el acceso a la tierra, pese a que estos últimos participaban como "amenaza y garantía" en las prácticas de justicia marginal.

Por supuesto que estos campesinos decimonónicos no son subalternos. En ningún momento se hacen representar y, al contrario, insertan sus expectativas y representaciones en los enunciados de la demanda, que no hace otra cosa que reproducir las normas y prácticas discursivas del Estado en la cotidianeidad.

En suma, una lectura hermenéutica, alejada de la extrema categorización, nos permite constatar la agencia política campesina en aquella relación entre estos pobladores y el Estado republicano. Insistir en la idea de "comunidades" o "pactos" republicanos alternativos sería desconocer precisamente la textualidad de la frondosa documentación judicial y reproducir enunciados de otredad y subordinación. $\mathrm{Al}$ contrario, lo que se constata son relaciones de política e identidad, que forman parte de luchas y procesos históricos protagonizados por los mismos campesinos.

\section{Agradecimientos}

El presente artículo forma parte de una amplia investigación respecto de la relación entre los campesinos de Ayacucho y el Estado peruano en el siglo XIX y fue presentado como ponencia en el IX Congreso Internacional de Etnohistoria, que se realizó en la Universidad de Tarapacá en noviembre de 2014. Deseo agradecer la asesoría de Karen Spalding y el apoyo de José Chaupis en la preparación de esta versión. Y también, agradezco los comentarios valiosos y las oportunas sugerencias de los anónimos evaluadores.

\section{Referencias Citadas}

Bonilla, $\mathrm{H}$.

1987 Ayacucho y su Población en el Siglo XIX: algunas consideraciones preliminares. Universidad de California, San Diego.
Burga, M. y A. Flores Galindo 1990 Apogeo y Crisis de la República Aristocrática, SUR / Fundación Andina, Lima. 
Cavero, L.

1953 Monografía de la Provincia de Huanta. Imprenta Rímac, Lima.

Contreras, $\mathrm{C}$.

1989 Estado Republicano y Tributo Indígena en la Sierra Central de la Posindependencia. Histórica 13: 9-44.

De la Cadena, $M$.

2004 Indígenas Mestizos. Raza y Cultura en el Cuzco. Traducido por A. De la Cadena y E. Neyra. Instituto de Estudios Peruanos, Lima.

Chatterjee, $\mathrm{P}$.

2007 La Nación en Tiempo Heterogéneo y otros Estudios Subalternos. Sephis / CLACSO / Instituto de Estudios Peruanos, Lima.

Del Pino, J.

1955 Las sublevaciones indígenas de Huanta, 1827-1896. Imprenta González, Ayacucho.

Del Pino, P.

1993 Ayacucho: economía y poder en el siglo XIX. Ideología 13: 5-23.

1994 Guerra, poder y campesinado: Ayacucho, 1879-1886. Tesis para optar el Grado de Bachiller en Historia. Universidad Nacional San Cristóbal de Huamanga, Ayacucho.

Díez, A.

1998 Comunes y haciendas. Procesos de comunalización en la sierra de Piura (siglos XVIII al XX). Centro Bartolomé de las Casas / CIPCA, Cuzco.

Geertz, C.

2003 La interpretación de las culturas. Traducido por A. Bixio. Gedisa, Barcelona.

Gootenberg, P.

1995 Población y Etnicidad en el Perú Republicano. Instituto de Estudios Peruanos, Lima.

Husson, $\mathrm{P}$.

1992 De la guerra a la rebelión (Huanta, siglo XIX). Instituto Francés de Estudios Andinos / Centro Bartolomé de las Casas, Cuzco.

Jacobsen, N.

1991 Campesinos y tenencia de tierra en el altiplano peruano en la transición de la Colonia a la República. Allpanchis 37: 25-92.

Jacobsen, N.

2013 Ilusiones de la transición: el Altiplano Peruano, 1780-1930. Traducido por J. Flores y N. Domínguez. Instituto de Estudios Peruanos / Banco Central de Reserva del Perú, Lima.

Guha, R.

1997 La prosa de la contrainsurgencia. En Debates Post Coloniales: una introducción a los Estudios de la Subalternidad, editado por S. Rivera y R. Barragán, pp. 33-72. Historias / Aruwiyiri / Sephis, La Paz.

1999 La muerte de Chandra. Historia y Grafía, 12: 49-86.

Joseph, G. y D. Nugent

2002 Cultura popular y formación del estado en el México revolucionario. En Aspectos cotidianos de la Formación del Estado, editado por G. Joseph y D. Nugent, pp. 31-52.

Era, México.

La Serna, M.

2013 Los huérfanos de la justicia: estado y gamonal en Chuschi antes de la lucha armada. En Entre la región y la nación. Nuevas aproximaciones a la historia ayacuchana y peruana, editado por R. Ayala, pp. 247-288. Instituto de Estudios Peruanos, Lima.

Mallon, F.

2003 Campesino y Nación: la construcción de México y Perú poscoloniales. Traducido por L. De la Vega. CIESAS / El Colegio de San Luis / El Colegio de Michoacán A.C., México.

Manrique, N.

1981 Campesinado y Nación: las guerrillas indígenas en la Guerra con Chile. Centro de Capacitación e Investigación / Ital Perú, Lima.

1988 Yawar Mayu: sociedades terratenientes serranas, 1879 1910. DESCO / Instituto Francés de Estudios Andinos, Lima.

Nugent, D. y A. Alonso

2002 Tradiciones selectivas en la reforma agraria y la lucha agraria: cultura popular y formación del estado en el ejido de Maniquipia, Chihuahua. En Aspectos cotidianos de la Formación del Estado, editado por G. Joseph y D. Nugent, pp. 175-213. Era, México.

Peralta, V.

1991 En pos del tributo en el Cuzco Rural, 1826-1954. Centro Bartolomé de las Casas, Cuzco.

Poole, D.

2009 Justicia y comunidad en los márgenes del estado peruano. En Repensando la subalternidad. Miradas críticas desde / sobre América Latina, editado por P. Sandoval, pp. 599-638. Sephis / Instituto de Estudios Peruanos, Lima.

Silva Santisteban, R. Spivak, G.

2006 Los Subalternos y el Perú. Hueso Húmero, 49: 133-144. Spivak, G.

2003 ¿Puede el subalterno hablar? Revista Colombiana de Antropología, 39: 297-364.

Trouillot, M.

1995 Silencing the Past. Power and the Production of History. Beacon Press, Boston.

Thurner. M.

2006 Republicanos Andinos. Traducido por J. Flores. Instituto de Estudios Peruanos / Centro Bartolomé de las Casas, Lima.

Urrutia, J.

2014 Aquí nada ha pasado: Huamanga, siglos XVI-XX. Instituto de Estudios Peruanos / COMISEDH / Instituto Francés de Estudios Andinos, Lima.

\section{Archivos y fuentes primarias}

Archivo Regional de Ayacucho (ARAy).

Archivo de la Dirección Regional Agraria de Ayacucho. 